\title{
Distraction and Boredom: Students Faced to Digital Economy
}

\author{
Fabienne Martin-Juchat ${ }^{1}$, Julien Pierre ${ }^{2}$, Aurélia Dumas ${ }^{3}$ \\ ${ }^{1}$ University Full Professor, Gresec, Université Grenoble Alpes, associated researchers at Grenoble Ecole de \\ Management, France \\ ${ }^{2} \mathrm{PhD}$, Gresec, Université Grenoble Alpes, associated researchers at Grenoble Ecole de Management, France \\ ${ }^{3} \mathrm{PhD}$ Student, Gresec, Université Grenoble Alpes, associated researchers at Grenoble Ecole de Management, France \\ Correspondence: Fabienne Martin-Juchat, Université Grenoble Alpes, GRESEC, Institut de la Communication et des \\ Médias, 11, avenue du 8 mai 1945 - BP 337 - 38434 Échirolles Cedex, France
}

Received: May 5, 2015 Accepted: May 12, 2015 Online Published: May 29, 2015

doi:10.11114/smc.v3i1.845

URL: http://dx.doi.org/10.11114/smc.v3i1.845

\begin{abstract}
The aim of this article is to understand the meaning of the emotional experiences students are faced with when giving attention (Beck \& Davenport, 2001) to techniques developed by the major players in the digital economy and its consequences on their future professional life. Our goal is to show, from a qualitative study, that the emotional dependence of the youth on digital technology generates a multi-active source of scatter and thus boredom. Only those who have mastered the time spent on these tools are satisfied. The students who are not bored have the ability to manage their time and productivity via digital resources. These results are the outcome of a study conducted over a two years period that investigates the new emotional spirit of capitalism, continuing the work of Boltanski and Chiapello (1999). It questions the emotional experience of students when faced with the dynamic of the economy's marketing techniques and its effect on attention (Illouz, 2006; Martin-Juchat, 2008, 2014).
\end{abstract}

Keywords: attention, students boredom, digital multi-activity, emotional experience, digital economy, productivity

\section{Introduction}

The aim of this article is to understand the emotional reaction of students when faced with attention based techniques developed by stakeholders in the digital economy and its consequences on their future professional life. Our goal is to demonstrate that the emotional dependency of the digital youth generates a multi-active source of distractibility scatter resulting in boredom. In the context of performance, only those who mastered the time spent on these tools are satisfied. The students who are not bored have the ability to control their time and their productivity via digital resources.

These results are from a study in communication sciences conducted by three researchers from the University of Grenoble-Alpes, over a two year period and on behalf of the Orange 'Digital Native' Chair of Grenoble Ecole de Management. This study examines the new emotional spirit of capitalism in continuing the work of Boltanski and Chiapello (1999). It questions the emotional experience of students when faced with the dynamic of the economy's marketing techniques and its affect on attention (Illouz, 2006; Martin-Juchat, 2008, 2014). In fact, companies such as Orange in France are facing the insertion of this new generation who has developed an addictive use of digital technology, which is expressed as multi-activity (play, watch, chat, buy and surf). They question the productivity of this generation.

We were privileged to be able to observe and question the use of digital technology by students from a higher education and build our observations from them. Our results highlight and question their future employability. After basing our theory and methodology on a collaborative approach, we will present the results obtained, following a second year of research. Lastly, we envisage using the perspectives of our present findings in order to guide our research.

\section{Theoretical Framework}

In the context of over- supply and an obsession with differentiation, the classification of emotions is the solution that the capitalistic economy has developed in order to continue to generate added value. The join, buy and convince experience is a strategy that is spreading widely (Illouz, 2006; Martin-Juchat, 2008).

According to Michel Foucault's definition of a device: 'being resolutely heterogeneous in terms of speeches, institutions, 
architectural improvements, regulatory decisions, laws, administrative measures, scientific statements, philosophical propositions, morals, philanthropy [...] an apparatus, therefore, is always written as a power game, but is also linked to one or more aspects of our wisdom, which we are born with but mostly are conditioned' (Foucault, 1994: 299), we postulate that contemporary capitalism relies on new operative terminals that we should know about: impact.

These devices also build emotional profiles: the personal profile is initiated and operated by customer segmentation, coupled with marketing/psychology and matched with consumers' needs. We buy because we want to; we feel emotions when we buy. Here, attachment, considered in terms of merchant exchange (Hardt, 2011), serves as the act of consumption, in a profit based relationship: economic and financial profit for the market leaders and emotional advantages for the consumers.

Additionally, the success of emotional capitalism is linked not only to a sociological movement marked by a desire for the rationalization of emotions, consistent with identification (as demonstrated by Eva Illouz, 2012), but also a necessity for capitalism to renew itself (Boltanski \& Chiapello, 1999); it involves purchasing services which creates the desired effect connected to a profile which the individual identifies with. However, only certain emotions from this social experience are valued.

Accordingly, the boredom felt by the students in their use of digital technology is a feeling that we can distinguish from other emotions. Drive and passion are strong reactions, which are involuntary and uncontrollable. Primary emotions are universal expressions (joy, anger, sadness, fear, surprise and disgust), and appear to be patterns of instinctive responses, barely developed, that function as passions. Secondary emotions and feelings are more diffuse and complex and less expressive, and manifest, for their part, in the form of conscious mental images that are relevant to cultural constructs (Damasio set out by Martin-Juchat, 2008).

Thus, as we can see, the feeling of boredom seems to be a social construction that students share when they associate a life experience (waiting for the bus, listening to a monotonous teacher, reading a mandatory text) representing signs of boredom, signs also promoted by communication professionals. We questioned students about their emotions in order to know their sentiments regarding digital technology. Indeed, the emotional logic of capitalism may also be perceived in all the emotional mechanisms such as sympathy, empathy, fusion, projection and identification.

However, what we mainly observed in this study is how the computer and the mobile phone merged with real emotional mediators and their relationship with others (see results below). According to our results, we can consider examining the efficiency of the emotional policy of capitalism. Indeed, the question of the extent of the influence on students remains unclear. Is boredom a statement of alienation, an admission of disenchantment with digital tools, a critique of capitalism, or the nourishing feeling of a capital-intensive strategy for never ending renewal of desire?

\section{Method}

Conducted in two stages (2012-2013; 2013-2014), this qualitative method encouraged a 'collaborative' approach, to prevent the interference of researchers during testing. During the first year, an exploratory study conducted with thirty students revealed boredom mostly felt in the face of a daily digital multi-active way of life (for more details on the results of this first year, see Martin-Juchat \& Pierre, 2013). During the second year, we refined the question of generalized boredom.

Workshops with voluntary student sessions helped to establish research protocol. Due to these times of exchange and sharing, we decided to combine both ethnographic type observations (two-way commenting in pairs) conducted by the students themselves and semi-structured interviews conducted by researchers presented a scoreboard and an interview guide made together during the workshops. We see the subjects as actors with a relevant, even expert, look at their own habits and uses of digital technology (Geertz, 1983; Martin-Juchat \& Zammouri, 2013). Also, every year we rebuilt a group of about 20 volunteer students, favouring research workshop meetings with a protocol of exchanges between researchers and students.

Each year, the first workshops were built around specific themes. During this time, we prepared the group of students for what would happen in the last workshop, with a guide for semi-structured interviews, as well as a chart in order to monitor/observe each pair. At the first workshop of the 2 nd year session, we presented the results of the exploratory study carried out on thirty students in the first year.

Students volunteered to conduct paired observations in various contexts: student A monitoring and recording the digital activities of student B. We thus agreed that the scoreboard, drawn up with the help of the participants, would serve as a support for discussions at feedback sessions between the researchers and established pairs. In the following monitoring chart we present a detailed summary of the progress made in the three workshops organized during the second year. 
Table 1. Detailed presentation of the workshops during the 2nd year

Workshop 1 (2 hours)
23 students
Presentation of the results of the
exploratory study (phase $12012-2013$ )
Presentation of the 'collaborative'
method
Subject of discussion: boredom
Procedure: 4 questions/From these
questions, students write keywords and
ideas on a post-it/time of reading of the
answers/time of exchanges and
discussions
Questions: 1) Why are you bored during
class? 2) What makes you bored when
you are using public transport? 3 ) What
makes you bored a when you're at
home? 4) When do you not get bored?

-report of workshop by a researcher as 'observer'

-transcription of all post-it and thematic analysis

Workshop 2 (2 hours) $\quad$ Workshop 3 (2 hours)

25 students

25 students

Subject of discussion: boredom (continued) and Reminder of the methodological multitasking/multi-activity

-Step 1:

3 discussion groups/one or two recorder students per group/exchange time and discussions

Themes: 1) How do you explain the paradox raised during workshop 1? Interaction during a class does not prevent boredom? Are digital tools a way of interaction? 2) What correlation is there between boredom and loneliness?

-Step 2:

Sharing of vocabulary: what is multitasking and multi-activity?

Categorization of multitasking and multi-activity: on post-it, students write digital activities that they associate with multitasking and multi-activity/answers/exchange time and discussions

Brainstorming: what activities do you associate with 'digital technology'?

-report of workshop by a researcher as 'observer'

-transcription of all post-it and thematic analysis

choices on the model of the

exploratory study (2012-2013):

observations and semi-structured interviews

Constitution of pairs for

observations

Development of scoreboard by students

Development of interview guide by students

Procedure: constitution of 5 groups/development of scoreboard and interview guide by groups/exchange time and discussions

-report of workshop by a researcher as 'observer'

-collection of students working documents for the finalization of the scoreboard and the interview guide by researchers

During 2013-2014, 13 pairs of volunteer students conducted 65 observations. At the same time, during the process, we also decided to complete our qualitative, semi-directed type of interviews with a sample of 30 students from various studies, as presented in the following summary.

Table 2. Detailed presentation of research method

\begin{tabular}{|c|c|c|c|c|c|c|}
\hline Observations in pairs & & & Semi-structured intervie & & & \\
\hline Number of pairs & $\begin{array}{c}\text { Themes of guided } \\
\text { Observation }\end{array}$ & $\begin{array}{l}\text { Analysis of } \\
\text { observations }\end{array}$ & $\begin{array}{c}\text { Number of people } \\
\text { interviewed }\end{array}$ & $\begin{array}{c}\text { Themes o } \\
\text { guided } \\
\text { interview }\end{array}$ & & $\begin{array}{l}\text { Analysis of } \\
\text { interviews }\end{array}$ \\
\hline 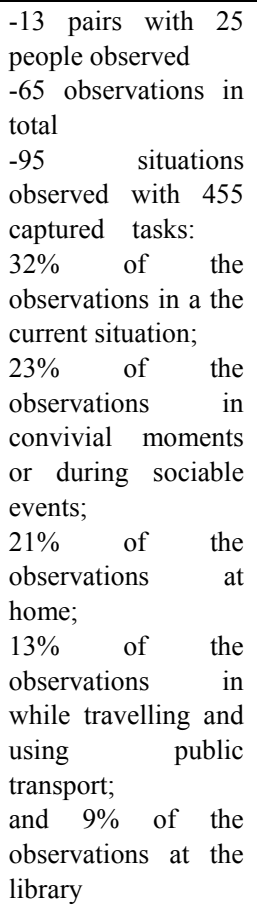 & $\begin{array}{l}\text {-step } 1 \text { observation phase: support } \\
\text { used, length of time taken, } \\
\text { incoming or outgoing context, } \\
\text { category of the transmitter or } \\
\text { receiver, digital applications and } \\
\text { types of activities } \\
\text {-step } 2 \text { debriefing phase: between } \\
\text { the observed and the observer on } \\
\text { the motivation and emotions felt } \\
\text { during the use of the digital } \\
\text { applications }\end{array}$ & $\begin{array}{l}\text {-one of the } \\
\text { researchers meets } \\
\text { each of the pairs and } \\
\text { establishes a fact } \\
\text { sheet } \\
\text {-transcription of the } \\
\text { entire observation } \\
\text { table and } \\
\text {-analysis } \\
\text { confrontation }\end{array}$ & $\begin{array}{l}\text {-30 students between } \\
18 \text { and } 25 \text { years old } \\
\text {-number of women: } 14 \\
\text { students } \\
\text {-number of men: } 16 \\
\text { students } \\
\text {-average age: } 20.7 \\
\text { years } \\
\text {-level of training: } 10 \\
\text { students L1, } 8 \text { students } \\
\text { L2, } 3 \text { students L3, } 4 \\
\text { students M1, } 5 \\
\text { students M2 }\end{array}$ & $\begin{array}{l}\text {-theme } \\
\text { digital } \\
\text { brands } \\
\text {-theme } \\
\text { digital } \\
\text { routines } \\
\text {-theme } \\
\text { digital } \\
\text { report time } \\
\text {-theme } \\
\text { digital } \\
\text { emotions } \\
\text {-theme } \\
\text { digital } \\
\text { identity }\end{array}$ & $\begin{array}{l}\text { 3: } \\
4:\end{array}$ & $\begin{array}{l}\text {-transcription of } \\
\text { each interview ( } 65 \\
\text { pages of verbatim) } \\
\text { - analysis of } \\
\text { content and } \\
\text { statistical results }\end{array}$ \\
\hline
\end{tabular}

Together with students from the study as well as the collected material and numerous exchanges between us, we were able to build a shared interpretation, which presents the results. 


\section{Results}

The results of this research confirm the tendency of the students to 'hyper-connect' and create a multi-active way of life, living between activities in the 'real' and 'virtual' world, dividing themselves between work and entertainment, as well as clarifying the reasons, modes of operation and emotional implications of this.

$63 \%$ of students feel that they spend more than three hours a day on their digital activities, their typical day being permanently using digital tools. Digital technology is therefore an integral part of their lives and the majority of students don't hesitate to associate it with the construction of their personal, social and professional identity. We interviewed them so that they could try to explain the boredom they felt so that we can understand their multi-active way of life.

\subsection{Boredom in the Face of Digital Technology}

Continuously connected, students make use of digital distractions during boring moments (breaks between two classes, waiting during public transit, moments of solitude, etc.). In the light of the results obtained during the exploratory investigation and following our exchange with students in workshops, we wanted to specifically understand the reasons of boredom felt in these situations, and the importance of the use of digital tools. We have also tried to understand what it means to them to not be bored.

Confiscated when they are not tolerated, these technological devices (mobile, notebook, and tablet) are temptations available to students who are bored. These digital activities are diverse and range from browsing on Facebook and responding to an SMS, to watching a movie. To justify their use, the users say they lack interest in the material being taught, as well as having to attend mandatory unwanted lessons that take place within a University in order to validate a training program. The need to implement this binding attachment is due to a high level of fatigue because of an extremely busy timetable, which they bitterly complain about. Despite it being a waste of time, they try to optimize their time with the use of digital technology and a multi-active lifestyle.

In addition, students criticize academic education for both its cognitive passivity (a 23 year old GEM student suggests 'a lack of intellectual stimulation. Its intellectual passiveness'), and a sensory-motor, self-disciplining body (Vigarello, 2004). The use of digital technology, which aims at regenerating interest, can be identified as attention seeking on many levels: cognitive, personal and emotional. As stated by a 19 year old IUT student 'when I'm bored, I use this time for digital use rather than doing what I should be doing. For example, when I would like to talk to this or that person, I send an SMS. When I would like to play, I play an easy game on my Smartphone, or I seek company on Facebook in order to make up for a lack of communication'.

Boredom as the source of the use of digital technology could, of course, be denied and blamed on other potentially boring things to do such as using public transport and having nothing to do at home. For many, beyond an intellectual mind, an interest in living things requires freedom of choice and an appreciation of time being seen as accelerated or even being rendered imperceptible ('not bored when one doesn't see the time pass by. Boredom does not exist', GEM student, 22 years old). It is mostly associated with the relationship of oneself to others. Digital tools are largely used when waiting and moving during public transit or at home, where the use is even more striking for students who are no longer living with their parents and end up alone at the end of their day.

Solitude appears to be the common denominator in the boredom felt within different contextual frameworks. Boredom, like solitude, opens a door for the self to discover one's own conscience and respond, understand or confront issues that tend to be bypassed in the presence of others. Searching for entertainment is then seen in 'Pascal' terms, i.e. as a refusal to think, the existential human who does not 'remain alone in a room' (Pascal, 1977: 118), unless perhaps digital tools are available so that man can forget himself, as we will see later.

\subsection{Multi-activity and the Quest for Emotional Intensity}

Here, we have chosen to speak about multi-activity and not multi-tasking (Lachaux, 2011), where it appears that students are more engaged in a succession of tasks rather than in tasks or activities carried out at the same time, although we can't exclude the use the digital tools by students as an indication of multi-tasking and we will examine this further. The use of digital technology runs parallel with the social life and activities of students. We wondered how students justify and organize the multi-active way of life they are involved in.

Considering multi-activity through the lens of emotions makes us think that students are looking for intense and diversified emotional stimulation. So we asked them about their motivations, triggers for the use of digital tools. Students ( $73 \%$ of students surveyed) generally thought that through their use of digital technology, they tend to feel more emotions. They also seek to increase the sources of emotional stimuli, intensifying the sensitive experience, in social spaces devoid of sentimentality, because not conforming to the social value of those who are not bored, promotes marketing creativity. This phenomenon easily fits into a modern socio-economic logic, which exploits the emotional target market (Illouz, 2006, 2012; Martin-Juchat, 2008, 2013, 2014) and tends to build an individual consumer affect. 
Immersed in 'Areas of consumption and communication with emotional added value' (Martin-Juchat, 2014), students build an intense emotional habitus (according to Bourdieu) that is filled with the use of digital tools, which creates power and even numbing. It is here that the spirit of emotional capitalism manifests itself.

The use of digital tools by emotional consumption creates a convenient loophole in the face of the banality of everyday life, and also against unwanted feelings that one would like to keep at a distance or reprogram. This digital entertainment takes the form of emotional entertainment: the use of digital technology creates a balance between feelings felt and the feeling felt in a social situation. For example, a student who experiences emotional distress or stress while in social situations, classroom situations or studying for tests, tries to relax/calm down while surfing entertainment sites that allow him to laugh, relax, or distract his mind in the direction of an idea or a nice image. A 22 year old UFR student referred to Facebook as an 'emotional moderator' to neutralize and remove negative emotions that do not fit into the immediate environment or are hostile to their expression. This self-regulating reprogramming of values can be viewed as 'emotional labor' (Hochschild, 2003); it enables one to master his feelings and conform to what is expected.

Additionally, observations carried out by the students revealed a strong emotional zapping - they move from joy to stress then laughter then back to stress and joy - corresponding to their digital activities. This multi-active way of life promotes these emotional outbursts that can be seen on the one hand, as a sign of finding emotional diversification giving the impression of the intensity of the present moment by emotional concentration, and on the other hand, as a complex balance between conflicting emotions. This type of emotion that creates renewed interest, and even excitement, in the face of boredom in an uncomfortable emotional situation, or in an unemotional environment, still runs the risk of emotional exhaustion by repetition right up until the loss of envy and desire. However, it is clear that this use of digital excitement also fits into a perspective of a routine that is almost of the order of thoughtlessness and ineffectiveness.

\subsection{Dependency and Habits}

Some students will succumb to digital diversion by habit, reflex, compulsion or addiction, thus forcing them into a delicate negotiation between (auto-)constraints and pleasures. Curiosity and the appeal of novelty are also powerful engines in the introduction of a multi-active way of life, confined to the anguish and the fear of missing information (FOMO - the fear of missing out, see Kandell, 1998).

Indeed, the use digital technology falls between work activities and entertainment, most students subscribing to the logic of gratification: the use of digital activities acts as a reward for consecutive efforts (long work activity). A student explained her workspace organization and said she needed a digital background in order to concentrate: 'when this is full I relax. Afterwards one is more productive'. Another student introduced 'work entertainment', in his own words, using Facebook continuously 'in case there is someone or some new information'. But the attempt of strict work-entertainment limits requires motivation and stubborn determination and seems difficult for some students to do and as they are tempted respond to the digital tool nearby, and they do so with guilt.

We wanted to understand this multi-active way of life through the time devoted to their various digital activities: is it zapping or longer activities? It is interesting to note a discrepancy between the results of observations by pairs and interviews, revealing a distortion between impressions and their practices. Interviews show that respondents distributed their activities almost equally between digital zapping and long digital activity. From the conducted observations, it appears that most of the paired activities were very short successive tasks that lasted 1 minute for $43 \%$ of them and between 2 and 5 minutes for $37 \%$.

Long so-called digital activities corresponded generally to activities related to academic work such as current note-taking or documentary research in the context of the teaching as well as in engaging in recreational activities such as watching movies and series, reading articles on news sites and online gaming. Zapping, meanwhile, included the fast checking and reading short texts, information sites, social networks, fast application games, and also watching movies and series, which can be part of a course during a meal with friends or in parallel to a searching or visiting other web sites. It appears that these activities are conducted and organized routinely, students admitting that they diversify their use of digital technology a bit.

All of the students in the survey said they had their own routines in the use of digital devices. Between reassurance through the need to control one's environment and the use of this technology that is not questioned, these routines need to be organized according to specific measures and time frames. Thus a student explains: 'I don't ever turn off my phone and I turn on my computer as soon as I wake up'.

This multi-active way of life causes a logic of distraction which appears to be a process in the course of normalization. This can be seen by the use of digital technology during classes, where the subject matter and/or the teacher himself might have the same level of interest and there is a strong active involvement by the students, without undermining the 
use of these digital tools. Besides situations, which are experienced as boring, the use of digital technology seems to be a routine action, without any appreciation for the emotional aspect (pleasant or unpleasant) of the living situation.

This automatic use of digital tools, which can be seen more and more in multi-activities and multi-tasking, can be understood as a way to manage many tasks at once, by this so-called generation of digital natives: it is these students who operate various activities with such synchronicity against a background of digital technology whose usage has become automatic

Omnipresent, routine-like or even integrated, do these digital tools,, with an established multi-active way of life, provide student satisfaction? What emotional relationships are maintained with this use of digital technology?

\subsection{An Ambiguous Emotional Relationship}

These digital entertainment-prone students demonstrate an ambiguous emotional rapport with regard to their own practices, oscillating between pleasure and constraint, constraint and auto-constraint, satisfaction and dissatisfaction.

Our exploratory study shows a strong emotional attachment to the brands associated with TIC. Also, we interviewed them about their relationship with the brands associated with digital technology. It is clear that students think digital technology is linked to technical support (computer, telephone). To the question, 'Can you designate 5 brands that you associate with your digital activities?', Apple, Samsung and Sony were the most cited, the social network Facebook was in fifth position, Twitter eighth place. Digital use is therefore only partly associated with their activities (mails, social networks, serious news information websites that they often go on to etc.), even though these are part of their daily routine. However, the emotional aspect only partly appears in their responses. Good quality, functionality, reputation and price are perceived as high added values in recognized brands. The emotional attachment, against all odds, is barely mentioned and several students even suggest that these brands have 'no added value' as summarized in the following table.

Table 3. Trademarks associated with digital technology and added values by number of occurrences

\begin{tabular}{lc}
\hline Associated added value & Number of occurrences \\
\hline Good quality & 53 \\
No added value & 21 \\
Functionality & 21 \\
Reputation & 21 \\
Price & 13 \\
Design & 10 \\
Innovation & 10 \\
Communication and sharing & 9 \\
Performance & 8 \\
Rapidity & 8 \\
Emotional attachment & 6 \\
Marketing & 3 \\
New products & 3 \\
Choice & 2 \\
Entertainment & 1 \\
Free of charge & 1 \\
No supplies & 1 \\
Personalization & 1 \\
Client relations & 1 \\
\hline
\end{tabular}

Several explanations highlight the relative absence of reference to their emotional attachment in their responses. The criticism they display in their remarks about the brands associated with digital technology appear to take a libertarian stance, corresponding to an ambient speech, flattering for the student 'consumer-actor' who sees himself as freely faced with these brands, saying it is worth it to mirror results between brands cited and used, which is evidence of the mass use of such brands. On the other hand, it could be a sort of denial of the partial loss of control that allows them to even remotely admit any attachment or addiction to oblivion, a sign of a lack of awareness of the obvious strength of digital brands, which is the only area of technical tools that is not understood by students. For this reason, many of them recognize the difficulties associated with the use of daily digital tools and applications. However, if their speech can be criticized in respect of brands associated with digital technology, they comment positively about applications involved in their rituals, often regarding entertainment. This oversight can therefore resemble an admission of dependence insofar as they did not seem to be aware of the trading strategies behind these applications by the major groups in the digital economy.

\subsection{Between Pleasure and (Self-)Constraints}

The use of digital applications provides students with both instant pleasure to the fact of their participation in the digital 
community, and self-recognition in terms of manipulation of the digital tool thus developing their skills. Digital content involves sharing with others, feeding exchanges between peers and filling moments of conversational gaps during meals or in the evenings.

This ability then slides onto the side of auto-constraint lived as an internalization of a hyper-connective way of life, falling within the logic of normal live. In this regard, disconnection is perceived as impossible, fuelled by the fear of marginalization. For a minority of students who do not wish to create a profile on Facebook, several respondents told us that it is a real 'handicap' for the group if they are to work with them for a presentation or for example, on projects. When asked about their opinions of these low users or those who don't use applications, the students seemed to be in a paradox between the freedom and acceptance of the standard norm: raising the character of the student capable not using the device, they are also aware that not using digital temptations is not difficult in itself, but becomes so when they attempt to stop, and so some identify this need as an addiction. However, for the majority of the surveyed students, the introduction of digital multi-activities remains unsatisfactory, not producing enchantment but rather feeding a sense of fatigue ('It's tiring to constantly use this technology', a 20 year old IUT student).

\subsection{How Does One Prevent Boredom?}

Submission to digital slavery, because you need to be entertained or belong to a group, they say, gives most of the students a global sense of dissatisfaction, weariness, regret and guilt, ultimately, from which some try to protect themselves against, through the development of 'crafts' (De Certeau, 1980).

In our many discussions with students during the workshops, the following paradox appeared: digital use creates boredom, which, in failing to appease, generates more boredom. We would like to prove this cyclic fight against boredom through the interviews we conducted. To the question 'do you understand this paradox: people use digital tools to combat boredom, but the use of the digital technology itself is causing problems? And is this the case for you?', most of the students recognized this as the case, speaking to us about a 'spiral of boredom' from which some find it difficult to escape.

Here, we agree with the results of the recent study of the digital life of adolescents (12 to 17 years old), by sociologist Joëlle Menrath, who found boredom through their use of digital. Our results also show that in teenagers and young adult (the age of our sample, ranging between 18 and 25 years old), this trend of boredom in digital use is confirmed.

They describe themselves as caught in a trap of boredom, which in itself brings dissatisfaction. This feeling is linked with the highly addictive nature of the use of the digital tools, understood by a number of students. Addiction, logically, is partly a loss of control which, at the same time, creates an exhaustive form of desire, which automatically feeds the boredom which it seeks to thwart ('When I'm bored, I use my computer or my laptop. This does not seem to decrease boredom, but it provides stimulation', 20 year old IUT student).

Digital zapping is a compulsive thirst for novelty and the hasty ingestion of a large amount of notifications and reading material, and boredom with the digital overview quickly results in the sustained fast pace of navigation. This digital 'bovarysme' is also explained by the weariness from the routine of their digital activities, which in return sharpens the impression of the ordinary from the emptiness of this use. Also, the question 'do you feel you lose or gain time in your digital lifestyle?' Why?', a majority of students believe they are wasting their time in their digital activities.

From analyzing these interviews where students indicated a feeling of wasting time in their digital usage, it appears that they are overwhelmingly dissatisfied; they assess advantages of their own uses according to a criteria of productivity.

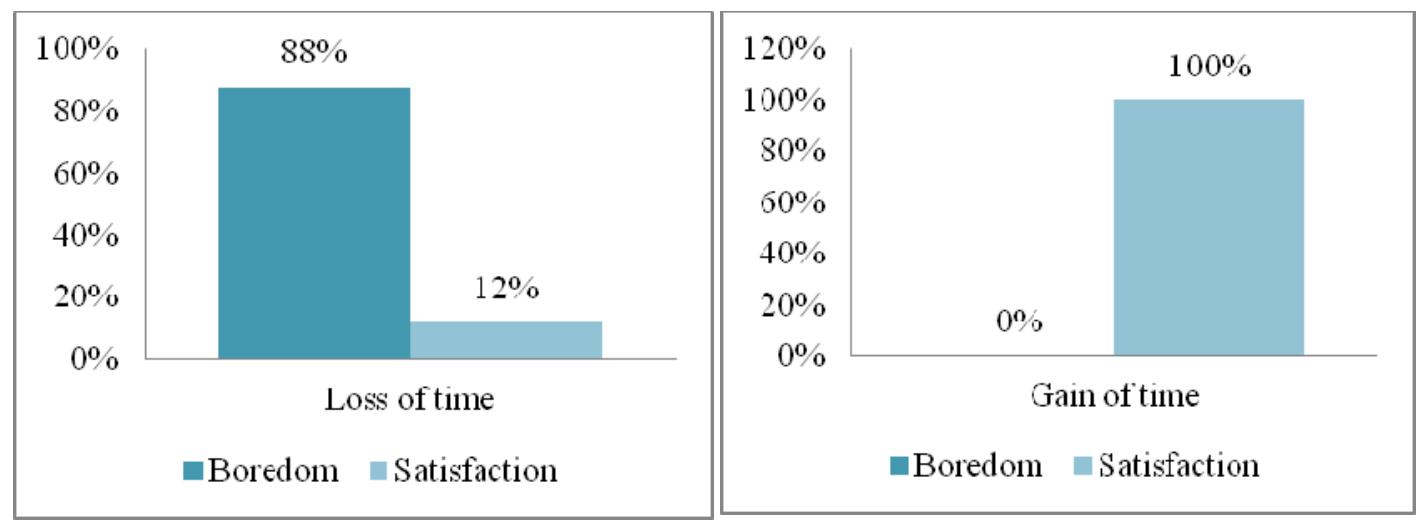

Figure1. Productivity and a sense of satisfaction 


\subsection{Control against Boredom}

It is clear that none of the students experienced the sensation of gaining time and have the impression of being bored with their digital activities (see figure 1). In the era of a fast paced society (Rosa, 2010), pleasure or displeasure seems to gauge the value of time allowed for these activities. By comparing the results obtained with the estimated time taken per day, gain or loss of time is portrayed as removed from satisfaction, it appears that students who manage to maintain control of their time, are satisfied overall. Conversely, the disgruntled students are mostly those who spend less time on digital tools, which can be explained by an unwillingness to respond to dissatisfaction, or those who dedicate a lot of time to digital activities. Out of 30 surveyed students, two of them who were estimated to use digital tools for more than 15 hours a day were, nevertheless, dissatisfied with their use. These heavy users (more than 10 hours per day) mostly feel that they save time in their academic work, but told us wasting this time in their recreational activities, thus generating frustration and remorse.

Logic of gain, according to the model of pragmatic rationality search performance, as suggested by modernity (Ehrenberg, 2010) seems therefore to justify their boredom and more widely explain the assessment of their own uses of digital activities. This same quest also encourages multi-active ways of life, perceived as time saving (manage emails; revise another course, shopping online, etc. while doing another activity). And a 22 years old GEM student told us: 'I need to perform several tasks at the same time in order to be happy with my own productivity'.

Therefore, for satisfied users, strategies are used to save time. Self-regulation, which may take the form of limiting digital activities through focused and dedicated time management (time to work with or without digital media / digital relaxing time / disconnection time), illustrates, on the one hand, a limitation of attention diversion sources as the main activity, to, on the other hand, a safeguard to limit time consuming digital wandering.

A student at the school of journalism suggests a new satisfaction that comes from managing and regulating digital use: 'I now try to detach myself [from digital tools], I've stopped hanging out on social media sites, as it was counterproductive. I looked at the same sites all day, continuously. I had a lot of tabs open, but I was not reading them. Then, due to too much digital use, I became exhausted. I hang out on sites less and less now; I do not take my PC with me during the day. I check my emails in the evening. It makes me feel good. In addition, I read more newspaper articles and I write more, since I have more time.' And he continued: 'It is not a problem when digital technology is well used'.

Moreover, the use of several digital devices (phone, Tablet, computer - fixed and laptop) enables some students to delegate certain mediums for certain tasks: for example, a student delegates his phone for fun applications, his laptop for emails, Facebook and viewing series and movies, his notebook for taking notes and his fixed computer for working from home, thus managing to limit the time of relaxation and work.

In the same way, a 20 year old IUT student, told us that he puts his mobile phone, which he always keeps with him, on to 'do not disturb airplane mode' or attempts to if he is in class, thus allowing him to engage more fully in the lesson.

Finally, another student told us that this same mode was required in managing SMS messaging, in the light of the amount of messages received per hour: 'I prefer to call now. It's tiring to write. I'm weary'. Initiated self-regulation is to be understood as the result of both a reflex with regard to limiting digital use, and also a learning effect.

Digital entertainment, when it is controlled and is not used in excess, can be an advantage insofar as providing immediate relaxation and oblivion at the very moment when it is needed, it can become even more effective when used after work. Some students combine entertainment and productivity by directing their distraction towards games that test their general knowledge while including friends, various forms of relaxation, emulation and competition. Another student has limited the number of playful applications on his phone and added applications 'of serious newspaper sites, which encourages him to go and acquire a general culture during break time'.

These modes of operation are tactics that can, in the interests of rationalization and compartmentalization of free time, avoid fragmentation and promote advantages. Here, it would be wise to question self-regulating crafts which are control mechanisms developed to combat wasted time, but are also emotional thus they contribute to an increase in self-esteem (Illouz, 2012).

\section{Perspectives}

Students, invested in a multi-active way of life, seem to have a complex emotional attachment to digital services, tinged with ambivalence, between boredom and satisfaction, pleasure and constraint, constraint and auto-constraint, in which they are partially invested. If they express a strong emotional attachment to their digital use, which is a standard and routine part of their day, in terms of social activities and generally in a continuous flow of attachment, this dependency and use could prove to be unsatisfactory, exhausting and empty.

Similarly, it appears that their permanent digital tool disposition is almost a reflex response to boredom, and even if this 
creates a problem, they seem unable to protect themselves against it. Multi-faceted, boredom, which is available on sensory-motor, cognitive, or ontological levels, is found by students to be a convenient stopgap in their digital use. Almost as soon as boredom is experienced, it creates the spiral use of more digital applications, which could result in a loss of control rather than the quest for novelty use, like an horizon of expectations, continually fed and without content.

Their deception must be understood firstly, in light of the pleasure that their digital use can provide in the sharing of entertainment, like space/time of ordinary socialization, and on the other hand, through the emotional excitement they receive by this. However, the emotional intensification, made possible by digital use, might become repetitive and boring.

The complexity of their relationship with digital technology is also reflected in their understanding of the brands they associate it with: they oppose a lack of added extras; they criticize the leaders of the market and represent themselves as pragmatic in their choice of tools, while recognizing, at the same time, a strong emotional dependency. This tension can appear on the one hand, as a sign of the desire displayed to avoid the influence of brands, which, on the other hand, would participate in the questioning of their individual capacities of resistance and free expression, and maintaining control of the tool, reduced here to its instrumental dimension.

From our research, it appears that the students most satisfied with their use of technology tools prove be strategic and more skilled in implementing their use of these tools, especially of the order of self-regulation. In a utilitarian way, their sense of satisfaction appears linked to productivity supposedly achieved by a multi-active way of life, whether in work or relaxation time: shared information, 'useful' entertainment, to give them the impression of enriching their time. On the contrary, when someone is unskilled or unproductive, the use of digital tools gives them the feeling that they're wasting their time, which results in disappointment coupled with guilt.

This multi-active way of life allows them to have continuous connection to many social spheres, in a reality that appears logical and normal for all, and requires skill, in terms of prioritization of responses to various temptations. Facing the risk of distraction, and developing emotional skills through mastering this way of life, could create a competitive advantage and become factors of social inequality. As stated by Eva Illouz, 'emotional competence is not only a form of capitalism that can perhaps be converted into share capital or promotion in the work world, but it is also a resource that helps members of the middle class gain access to a form of happiness or at least of well-being, in the private sphere' (Illouz, 2006: 129). However, it must be noted that some students lack the resources needed to manage and control digital technology.

The need for collective thought with this type of learning is felt even more by the marked inequalities, which may be discriminatory during an important academic period in their professional future ${ }^{1}$.

${ }^{I}$ Our restricted sample (30 people surveyed) appears as a limitation of our research. Futhermore, this young people are students so it would be relevant to confirm our results with a wider sample, more representative of digital technology young users as a whole, which is our perspective of research.

\section{References}

Beck, J., \& Davenport, T. (2001). The Attention Economy: Understanding the New Currency of Business. Cambridge: Harvard Business School.

Boltanski, L., \& Chiapello, E. (1999). Le nouvel esprit du capitalisme. Paris: Gallimard.

Certeau, M. (de) (1980). L'invention du quotidien. Arts de faire. Paris: Gallimard.

Dumas, A., Martin-Juchat, F., \& Pierre, J. (2014). Vers des bricolages stratégiques pour faire face à l'ambivalence affective du rapport au numérique. rapport annuel pour la Chaire 'Digital Natives', Grenoble: Grenoble Ecole de Management, Orange, from http://www.grenoble-em.com/2289-publications-et-recherche-1.aspx

Ehrenberg, A. (2010). Le culte de la performance. Paris: Pluriel (1ère édition 1991).

Foucault, M. (1994). Dits et écrits. Paris: Gallimard.

Geertz, C. (1973). The Interpretation of Cultures. New York: Basic Books.

Hardt, M. (2011). For love or money. Cultural Anthropology, 26(4), 676-682. http://dx.doi.org/10.1111/j.1548-1360.2011.01119.x

Hochschild, A. R. (2003). Travail émotionnel, règles de sentiments et structure sociale. Travailler 1(9), 19-49. http://dx.doi.org/10.3917/trav.009.0019

Illouz, E. (2002). The Culture of Capitalism. Jerusalem: Israel University Broadcast.

Illouz, E. (2012). Why love hurts: A sociological explanation. Cambridge: Polity Press. 
Kandell, J. (1998). Internet addiction on campus. The vulnerability of college students. Cyberpsychology \& behavior, 1(1), 11-17. http://dx.doi.org/10.1089/cpb.1998.1.11.

Lachaux, J. P. (2011). Le cerveau attentif. Contrôle maitrise et lâcher-prise. Paris: Odile Jacob.

Martin-Juchat, F. (2008). Le corps et les médias: la chair éprouvée par les médias et les espaces sociaux. Bruxelles: De Boeck. http://dx.doi.org/10.3917/dbu.marti.2008.03

Martin-Juchat, F. (2014). La dynamique de marchandisation de la communication affective. RSFSIC, $\mathrm{n}^{\circ}$. http://rfsic.revues.org/1012.

Martin-Juchat, F., \& Pierre J. (2013). Usages affectifs des Tics par la jeune génération. Le numérique pour tromper l'ennui au travail. http://www.brunoasdourian.fr/actes-colloque-org-co-2013.pdf

Martin-Juchat, F., \& Zammouri, H. (2013). Expérimenter les relations entre artistes et scientifiques: l'appropriation de capteurs de mouvement par des danseurs. Journal for Communication Studies, 6(1). http://www.essachess.com/index.php/jcs/article/view/199

Menrath, J. (2014). Les ados s'ennuient aussi avec les outils numériques, Observatoire de la vie numérique des adolescents. http://www.fftelecoms.org/articles/les-ados-s-ennuient-aussi-avec-les-outils-numeriques.

Pascal, B. (1977). Les Pensées. Paris: Gallimard.

Rosa, H. (2010). Alienation and acceleration. Towards a critical theory of late-modern temporality. Stockholm: Nordic Summer University Press.

Vigarello, G. (2004). Le corps redressé. Paris: Armand Colin.

\section{(c) $\mathbf{E Y}$}

This work is licensed under a Creative Commons Attribution 3.0 License. 